\title{
Reseña. Osvaldo Rodríguez Musso, El día que me quieras. Viña del Mar: Ediciones Altazor, 20141.
}

Desde una década antes de la dictadura de 1973 en Chile, hasta la postdictadura, el nombre de Osvaldo “Gitano” Rodríguez Musso (Valparaíso, 1943 Bardolino, 1996) ha estado asociado a la vida cultural de Valparaíso, en especial como cantautor y estudioso de la Nueva Canción Chilena, "era popularísimo por una de sus canciones, titulada simplemente «Valparaíso», la que había opacado al resto de su producción musical, prosística, poética y visual" (Castagneto 139). Sin embargo, su polifacética actividad creadora abarca también a la poesía y la novela.

En el campo de la musicología, dos textos son fundamentales: Cantores que reflexionan. Notas para una historia personal de la Nueva Canción chilena (1984) publicado por Ediciones LAR en Madrid, y reeditado el año 2015 por Editorial Hueders en Santiago de Chile, y La Nueva Canción chilena, continuidad y reflejo (1988), publicado por la Editorial Casa de las Américas en Cuba, basado en su tesis doctoral en la Universidad de Praga. Lo que se propone en estos textos es analizar “el devenir de la canción chilena y su vínculo con la poesía, la raíz folclórica y el

${ }^{1}$ Esta reseña está vinculada al proyecto CONICY + FONDECYT/Postdoctorado $2016+3160779$ "Narrativas marginales de/sobre Valparaíso: una mirada analítico-crítica a los imaginarios de resistencias a la modernización 1925-1980". 
compromiso político" (García 10) poniendo en valor una serie de obras musicales que, hasta ese momento no eran reconocidas en los círculos oficiales (15). Sin embargo, estos estudios no fueron bien recepcionados ni por su pares ni por la crítica oficial pues el autor no sólo "eligió convertirse, también, en un agitador cultural -a través del pionero trabajó en peñas, en los años 60" (11) apoyando, como muchos de su generación, la candidatura de Allende, y el proyecto de la Unidad Popular (Campos 18; Merino 10; Morris 149), sino que, además, descarta hablarles a los eruditos, pues en los análisis desarrollados en sus estudios, las "descripciones y anécdotas establecen un vínculo entre su curiosidad y la de cualquier chileno atento a su tiempo, aunque diferenciadas por la agudeza de una narración que buscaba trascender la coyuntura" (García 12), gesto que lo distancia del discurso académico. Pero su estudio también fue incomprendido por los músicos y cantantes citados y referenciados, pues, como él mismo lo reconoció en su momento, "Las fotocopias y capítulos sueltos que circulan de este trabajo me han dado unas cuantas satisfacciones pero también varios dolores de cabeza" (Rodríguez, Cantores 27).

En relación a su poesía, las obras publicadas en vida por Osvaldo Rodríguez son tres: Estado de emergencia (1972), Diario de doble exilio (1975) y Cantos de extramuros. Poemas (1994). La vivencia del exilio expresada en los dos últimos tiene la singularidad de apartarse de la rememoración melancólica de la nación o la patria perdida, fijando la reconstitución de la memoria en la comunidad de origen, es decir, en el imaginario de Valparaíso, lo que se instituye en un gesto transgresor, pues,

Se debe constatar que la propuesta contra-hegemónica de los escritores e intelectuales del exilio, fue, ha sido y sigue siendo pensada desde la imagen de la nación y no desde la comunidad de filiación más próxima, siendo este uno de los motivos por el cual esta poesía, hasta el momento, ha permanecido en los márgenes. (Figueroa y Herrera 45) 
El locus poético del "Gitano" Rodríguez es Valparaíso, estableciendo una relación nostálgica constructiva con el imaginario de la ciudad-puerto, determinada por una pulsión erótica, en el sentido de una relación irénica, pero no menos agonal, con la poética de la ciudad, como una influencia seducida, en el sentido de ser el "resultado de un tipo de juego que, como el juego 'a secas', pertenece a la esfera de la 'liminalidad', siendo, además, un umbral tras el cual se abre el territorio de lo poético hacia una intertextualidad amorosa" (Ivanovici 53-54). Nos parece que cabría pensar la poesía del "Gitano" Rodríguez situada desde una específica intertextualidad amorosa en y con el imaginario de Valparaíso, y en una relación conflictiva, agonal, con la representación hegemónica de lo nacional, que lo pone en una situación de doble marginación, "ya que a la marginalidad propia del exilio con su correspondiente política cultural homogeneizadora impuesta desde el poder, se suma su rasgo de escritor provinciano" (Figueroa y Herrera 45).

A modo de ilustración se puede consultar el artículo de Fernando Jerez "Generación del 60: escribir en dictadura" (2002), en el que hace el recuento de lo que denomina como "Generación del 60", en especial en el Anexo 2, donde se exponen los criterios clasificatorios que cinco críticos elaboran para dicha generación (113-117). Estos criterios están, más allá de matices, cronológicos, sustentados en dos categorizaciones no excluyentes: escritores nacidos entre 1935 y 1950, o que empezaron a producir obras entre los años 1965 y 1979. Cabe destacar que el autor porteño calza en ambas, sin embargo no aparece mencionado por ninguno de los críticos expuestos. Por otra parte, Manuel Jofré, en su estudio "Ensayo sobre el exilio: Literatura chilena por el mundo" (1995), propone una teorización sobre la literatura del exilio, cualificándola como una escritura que tiene como "personaje principal a Chile, y que desde la distancia, interpela a la sociedad chilena, y con ello se vuelve parte de ella" (35), no haciendo la más mínima mención de nuestro autor.

En relación a la recepción en el medio literario porteño, es significativa la ausencia de mención a Rodríguez Musso en el exhaustivo estudio recopilatorio de Claudio Solar Historia de la literatura de Valparaíso (2001), en el que se da cuenta 
de otros poetas y escritores de la ciudad-puerto en el exilio, como Juan Camerón (5 y 96), Eduardo Embry (91 y 92) y Luis Mizón (94). Lo mismo acontece en su artículo "Contactos literarios con Valparaíso" (1986) en el número especial que la revista Atenea le dedica a la ciudad-puerto, en el que hay una total ausencia de referencias a su obra, incluso en la "Antología poética porteña" seleccionada, en la que aparece un poema de Mizón (100). Por contraparte, aparece destacado por Piero Castagneto en El Valparaíso de los escritores (2013), quien lo sitúa en la generación del 80, como un poeta del exilio, siendo uno de "sus exponentes destacados en el ámbito creativo" (138).

Lo relevante para nuestro análisis, es que en ninguno de los documentos revisados se alude a la novela de Osvaldo "Gitano" Rodríguez, El día que me quieras (1987), la que, hasta donde se ha podido constatar, no ha sido suficientemente reseñada desde la crítica literaria nacional. Esto puede ser atribuido al hecho de que, si bien fue escrita en el exilio, se publicó por primera vez el año 2014 en Viña del Mar, por lo que sería poco probable que haya sido conocida por los críticos, analistas y antologadores de la literatura chilena en el exilio. Sin embargo, en base a los estudio de Nancy Morris sobre la correspondencia del "Gitano" Rodríguez, se sabe que él tuvo una especial predilección por la escritura epistolar, en las cuales no sólo se informaba de la situación del país de su familia y de sus amigos, pues, además de contar las peripecias de su exilio, compartía su quehacer académico y comentaba el avance de sus obras, ya que "Durante todos esos cambios personales, académicos y geográficos, Rodríguez mantenía una activa correspondencia epistolar" (150), que aún permanece inédita.

Teniendo en consideración el contexto descrito, lo que nos interesa destacar de la novela son dos elementos que cuestionan la forma como han sido imaginadas y narradas las experiencias del Golpe de Estado de 1973, la represión política y el exilio chileno. Por un lado, la configuración de un relato que no se sitúa en el horizonte del golpe militar, ya sea inmediatamente antes o después de su acontecer, sino que se instala una década antes del triunfo de la Unidad Popular lo que permite reconstituir el conflicto de clases no resuelto que agudizará el conflicto político. Si 
bien la trama está teñida del sabor de una historia de tortuoso amor adolescente, narrada desde un sutil erotismo masculino, lo develado son los registros imaginarios y simbólicos presentes en los jóvenes de la alta burguesía de Valparaíso durante el proceso de ascenso del socialismo, desde una posición de privilegio socio-económico y cultural como una determinación de clase, tensionando la relación entre biografía y texto literario, y entre subjetividad y potencia colectiva.

Por otro parte, la hegemónica representación de la pérdida producto del exilio, desde la melancolía nacionalista como lugar natural de la constitución de una comunidad añorada, es desactivada desde una nostalgia que destituye el lugar del origen en la búsqueda de una comunidad a constituir. Como señala Jofré, "Esta cultura chilena en el exilio difiere del producto artístico del interior, y sin embargo, es parte de ese mismo sistema cultural nacional perteneciente a la formación social llamada Chile" (37), reafirmando el carácter nacionalista de las interpretaciones hegemónicas. Esto se diluye en el caso de Rodríguez Musso, pues en su escritura "Valparaíso se convierte en una suerte de ciudad mosaico, construida en un estado de ensoñación rememorante, mediante la yuxtaposición de distintos fragmentos que el trato con el mar ha ido arrojando históricamente en la ciudad" (Nordenflycht 79). Es este mosaico el que articula el imaginario diferencial que cruza la obra del “Gitano” Rodríguez, lo que pone en evidencia el carácter contingente de los valores nacionales, constatando que, "Su radio de validez no era solo temporal, sino también regional, espacial" (Schopf cit. en Jofré, 43). A partir de esto, postulamos que la novela de Rodríguez Musso, a partir de la nostalgia constructiva con la que elabora sus textos, disloca el modo de representación de la literatura del exilio desde un imaginario nacionalista, lo que nos lleva a cuestionar la hegemonía del canon metropolitano desde la constitución de una literatura situada en y desde el imaginario de Valparaíso.

De esta manera, la escritura que desarrolla el "Gitano" Rodríguez en sus textos, tanto teóricos como literarios, -siendo difícil distinguir entre uno y otro-, deviene en una doble marginalidad: la de ser expresión de la condición de un escritor de provincia que se sitúa en una disputa agonal con sus antecesores situados 
en el canon nacional, con un fuerte sentido político y social, y la de ser un escritor del exilio que se desplaza de la rememoración nacional a la nostalgia constructiva del lugar de origen. En este sentido concordamos con la crítica al canon expresada por Figueroa y Herrera cuando afirman que, "para el caso chileno esa condición política y social preponderante que atraviesa su literatura y las consideraciones que la crítica literaria chilena ha hecho de ella, es el exacerbado centralismo que recorre su historia política y cultural desde la colonia hasta nuestros días” (43).

En la novela, además, se hacen visibles algunas dimensiones conflictivas del proceso de construcción de la vía chilena al socialismo, tales como la crisis de valores que llevó a la alta burguesía nacional, y porteña en lo particular, a confrontarse con las transformaciones políticas, sociales y culturales desde abajo, instalando un conflicto que desembocará en el Golpe de Estado. Esto también tiene un correlato en la crisis implícita en la constitución de una subjetividad politizada, que se posicionan crítica y activamente frente a los acontecimientos que le han tocado experienciar, desactivando las filiaciones que lo marcaban. Este conflicto se presenta en la novela desde las tensión entre biografía y memoria social, en las que se entrelazan la dimensión individual y colectiva del conflicto:

Se internó en los muelles observando el movimiento de los cargadores y la acción de las enormes grúas que cargaban los navíos. "Estos son los buques de los que habló el abuelo. [...] ¿Por qué no hay buques nacionales? ¿Qué pasa con el país? ¿Por qué hay tanta gente pobre? ¿Cómo es posible que los campesinos no tengan escuela donde aprender a leer? ¿Cómo es posible que nuestra familia tenga propiedades en el campo y en la ciudad? ¿Cuál es la verdadera historia de mi familia? ¿Cómo podré hacer para un día contribuir [...] a que todo cambie un poco? ¿Podré de verdad hacer algo? ¿Tendré que ir a pelear a una guerra como Sergio? Pero Sergio me dijo alguna vez que se sintió derrotado. ¿Si Sergio se siente derrotado, que queda para mí?”. (Rodríguez Musso 351-352) 
Si bien no podemos desconocer que la obra de Osvaldo Rodríguez Musso ha sido entregada de la retórica del silencio (Herrera A.) por parte de la crítica especializada, esperamos que esta reseña motive su lectura, para que sea valorada en su singularidad a partir de sus aciertos.

\section{Bibliografía}

Campos, Javier. La joven poesía chilena en el período 1961-1973, Concepción: LAR, 1987.

Castagneto, Piero. El Valparaíso de los escritores, Valparaíso: RIL, 2013.

García, Marisol. "Ideas sobre la canción”. Rodríguez Musso, Osvaldo. Cantores que reflexionan. Notas para una historia personal de la Nueva Canción Chilena, Santiago de Chile: Hueders, 2015. 9-20.

Herrera Alarcón, Ricardo. Panoptismo, silencio y omisión en la crítica literaria bajo dictadura, Valparaíso: Ediciones Inubicalistas, 2016.

Figueroa Flores, Ximena y Herrera Pardo, Hugo . "Hacia una poética "provinciana" del recuerdo: estar aquí/ser allá en la obra literaria de exilio de Osvaldo Rodríguez Musso". Logos: Revista de Lingüística, Filosofía y Literatura, 21.1, 2011: 40-52.

Ivanovici, Victor. "La intertextualidad amorosa". Tópicos del Seminario, núm. 14. 2005: 51-66.

Jerez, Fernando. "Generación del 60: escribir en dictadura", Karl Kohut y José Morales Saravia editores. Literatura chilena hoy: La difícil transición, Madrid: Iberoamericana / Frankfurt: Vervuet: 2002. 101-116.

Jofré Berrios, Manuel. "Ensayo sobre el exilio: Literatura chilena por el mundo" en Literatura chilena actual: cinco estudios (Narrativa, Poesía, Crítica, 
Ensayo y Testimonio), Santiago de Chile: Universidad Católica Blas Cañas, 1995: 34-48.

Merino, Carolina. "Entre la cohesión y la diáspora. 25 años de poesía chilena".

Aisthesis, 24. 1991: 9-19

Morris, Nancy. "Las peregrinaciones del Gitano exiliado: La correspondencia de Osvaldo Rodríguez". Exiliados, emigrados y retornados chilenos en América y Europa, 1973-2004, José del Pozo Artigas coordinador. Santiago de Chile: RIL, 2006. 149-165.

Nordenflycht, Adolfo de. "Poesía de la distancia en Valparaíso: exilio, memoria y lugar de enunciación en Eduardo Embry, Luis Mizón y Osvaldo Rodríguez Musso". Taller de Letras, 52, 2013: 69-84.

Rodríguez Musso, Osvaldo. Cantores que reflexionan. Notas para una historia personal de la Nueva Canción Chilena, Santiago de Chile: Hueders. 2015.

Rodríguez Musso, Osvaldo. Canto de extramuros. Poemas, Valparaíso: Umbral Editores. 1994.

Solar, Claudio. Historia de la Literatura de Valparaíso, Valparaíso: Ediciones de la Gran Fraternidad de Escritores y Artistas de Valparaíso. 2001.

---. «Contactos literarios con Valparaíso», Atenea. Revista de Ciencia, Arte y Literatura, 453 - 454. 1986: 49-77. 